chẽ giữa $B M D$ cột sống thắt lưng và cổ xương đùi với LDLC. Có mối tương quan đồng biến giữa $L D L-C$ và mật độ xương ở cả 2 vị trí CSTL và CXĐ. Ở mật độ xương CSTL có hê số tương quan $r=0,09$. Tuy nghiên sự khác biệt không có ý nghĩa thống kê với $p=0,1$. Còn ở mật độ xương CX甲 có hệ số tương quan là $r=0,22$, sự khác biệt có ý nghĩa thống kê với $p<0,001$ (bảng 3.4). Kết quả này tương tự như kết quả nghiên cứu của MK Garg, S.Adami.

\section{KẾT LUẬN}

Phần lớn loãng xương gặp ở nhóm tuổi $\geq 80$. Tuổi trung bình của nhóm loãng xương là $73,3 \pm$ 7,6 . Chủ yếu gặp ở nữ giới $(93,6 \%)$. Mật độ xương giảm dần theo tuổi ở cả 2 vị trí CSTL và CXĐ $(p<0,05)$. Khả năng người bệnh tập thể dục không có loãng xương cao gấp 1,8 lần người không tập thể dục $(95 \% \mathrm{CI}: 1,3-2,4)$. Nguy cơ người có bệnh lý nền xuất hiện tình trạng loãng xương cao gấp 2,37 lần những người không có bệnh lý nền (95\%CI: 1,8-3,1). Mật độ xương ở cột sống thắt lưng và mật độ xương ở cổ xương đùi có mối tương quan nghịch với Cholesterol TP, Triglycerid và $\mathrm{HDL}-\mathrm{C}(\mathrm{p}<0,01)$. Ngược lại, mật độ xương ở cột sống thắt lưng và mật độ xương ở cổ xương đùi có mối tương quan thuận với $\mathrm{LDL}-\mathrm{C}$.

Lời cảm ơn: Chúng tôi xin chân thành cám ơn những người bệnh Khoa khám bệnh, khoa khám bênh theo yểu cầu, khoa nôi tiết và cơ xương khớp Bệnh Viện Lão Khoa Trung Ương và Bộ môn Nội Tổng Hợp, Bộ môn Lão Khoa, Trường Đại học Y Hà Nội đã tạo điều kiện đế thực hiện nghiên cứu.

\section{TÀI LIỆU THAM KHẢO}

1. https://www.news-medical.net/health/BoneDisease.aspx. Last Updated: Oct 31, 2017.

2. Bone Disease. News-Medical.net. Published August 12, 2009. Accessed September 22, 2021. https://www.news-medical.net/health/Bone-

Disease.aspx

3. Garg MK, Marwaha RK, Tandon N, Bhadra K, Mahalle $\mathbf{N}$. Relationship of lipid parameters with bone mineral density in Indian population. Indian J Endocrinol Metab. 2014;18(3):325-332. doi:10.4103/2230-8210.131165

4. Kim T, Park S, Pak Y-S, Lee S, Lee E-H. Association between metabolic syndrome and bone mineral density in Korea: the Fourth Korea National Health and Nutrition Examination Survey (KNHANES IV), 2008. ] Bone Miner Metab. 2013; 31(6):652-662. doi:10.1007/s00774-013-0459-4

5. William C. Shiel Jr, M., FACP, FACR. Osteoporosis Treatment, Medication, symptoms, prevention... MedicineNet on health.com. Published online 2012.

\title{
ĐÁNH GIÁ BƯớC ĐẦU KÊTT QUẢ NUÔI CẤY PHÔI BẰNG MÔI TRƯờNG ĐƠN BƯỚC CSC TẠI BÊ̂NH VIỆN ĐẠI HỌC Y HÀ NộI
}

\section{Tạ Thị Quỳnh Giao', Bùi Thanh Thủy ${ }^{1}$, Nguyễn Khang Sơn ${ }^{2}$}

\section{TÓM TẮT}

Mục tiêu: Đánh giá bước đâu kết quả nuôi cấy phôi bằng môi trường đơn bước CSC và xác định một số yếu tố liên quan. Đối tượng và phương pháp nghiên cứu: Nghiên cứu quan sát, mô tả theo dõi dọc trên 66 phụ nữ làm thụ tinh trong ống nghiệm với 806 noãn MII được ICSI tại Trung tâm Hố trợ sinh sản, Bệnh viện Đại học Y Hà Nội, từ tháng 1/2021 đến tháng $8 / 2021$. Trong đó có 479 noãn sau ICSI được theo dõi nuôi cấy liên tục đến ngày 5 bằng môi trường đơn bước CSC có thay mới môi trường vào ngày 3 . Các biến nghiên cứu chính là tỷ lệ thụ tinh, chất lượng phôi giai đoạn phân cắt (ngày 2), chất lượng phối nang và một số yếu tố liên quan. Kết quả: Tỷ lệ thụ

\footnotetext{
${ }^{1}$ Trường Đại học Y Dược Thái Nguyên ${ }^{2}$ Trường Đai hoc Y Hà Nôi

Chịu trách nhiệm chính: Nguyễn Khang Sơn

Email: khangson@gmail.com

Ngày nhận bài: 19.7.2021

Ngày phản biên khoa hoc: 6.9.2021

Ngày duyệt bài: 20.9.2021
}

tinh đạt $91,66 \pm 12,92 \%$, tỷ lệ tạo phôi ngày 2 là $98,34 \pm 5,40 \%$, tỳ lệ tạo phôi nang là 73,07 \pm $13,06 \% \%$, tỷ lệ phôi nang hữu dụng đạt $69,81 \pm$ $12,96 \%$. Chất lượng noãn và tinh trùng tại thời điểm ICSI ảnh hưởng đến tỷ lệ thụ tinh, tỷ lệ phôi nang hữu dụng, sự khác biệt có ý nghĩa thống kê $(p<0,05)$.

Tư khóa: Phôi giai đoạn phân cắt, phôi nang hữu dụng, nuôi cấy phôi, môi trường đơn bước, môi trường chuyển tiếp.

\section{SUMMARY \\ RESULTS OF EMBRYO CULTURE BY CSC SINGLE-STEP CULTURE MEDIUM AT HANOI} MEDICAL UNIVERSITY HOSPITAL

Objectives: The study aims to initially evaluate the results of embryo culture using CSC single-step medium and compare with the results of embryo culture in transition medium. Subject and method: A prospective study was conducted on 66 women having IVF with 806 MII oocytes obtained by ICSI at the IVF Center, Hanoi Medical University Hospital, from August 2020 to August 2021. In which, 479 oocytes after ICSI were cultured continuously until day 
5 by CSC single-step medium with day 3-refreshment. The key variables were evaluation of fertilization rate, embryo quality in cleavage stage (day 2), blastocyst quality and some related factors. Result: The fertilization rate, the day 2 embryo rate, the blastocyst rate and the utilization blastocyst rate were $91.66 \pm$ $12.92 \% ; 98.34 \pm 5.40 ; 73.07 \pm 13.06 \% ; 69.81 \pm$ $12.96 \%$ respectively. Oocytes and sperms quality affects fertilization rate, the utilization of blastocysts rate, statistically significant $(p<0,05)$.

Key words: Cleavage stages embryo, utilization blastocyst, embryo culture, single-step media, sequential media.

\section{I. ĐẶT VẤN ĐỀ}

Sự phát triển của IVF trong hơn 40 năm qua gắn liền với những thay đổi và cải tiến trong hệ thống nuôi cấy phôi, đặc biệt là môi trường nuôi cấy. Mặc dù phương pháp thụ tinh trong ống nghiệm (IVF) đã ra đời từ lâu song việc lựa chôn điều kiện và môi trường nuôi cấy phôi tối ưu vẫn còn là một thách thức lớn. Hai phác đồ nuôi cấy phôi được sử dụng phổ biến hiện nay là sử dụng môi trường chuyển tiếp và môi trường đơn bước. Môi trường nuôi cấy chuyển tiếp gồm hai loạ môi trường được thiết kế với những thay đổi nhằm phù hợp với sinh lý của phôi giai đoạn trước và sau nén [1]. Ngược lại, môi trường nuôi cấy đơn bước chỉ sử dụng một loại môi trường mà vẫn có thể cung cấp đầy đủ yếu tố cần thiết cho phôi phát triển ở tất cả các giai đoạn [2]. Mỗi phác đồ đều có ưu nhược điểm riêng. Việc đánh giá hiệu quả nuôi cấy phôi giữa 2 phác đồ đã được nghiên cứu và ứng dụng tại nhiều trung tâm IVF lớn trên thế giới cũng như tại Việt Nam [3], [4]. Mặc dù chưa đưa ra được kết luận môi trường nào là tối ưu nhưng xu hướng hiện nay là thực hiện nuôi cấy phôi bằng môi trường đớn bước.

Tại Trung tâm Hỗ trợ sinh sản - Bệnh viện Đại học Y Hà Nội, từ năm 2020 bắt đầu tiến hành nuôi cấy phôi hoàn toàn trong môi trường đơn bước Continuous Single Culture (CSC) nhưng chưa có một nghiên cứu nào đánh giá kết quả nuôi cấy phôi trong điều kiện này. Chính vì vậy câu hỏi đặt ra là liệu việc nuôi cấy phôi trong môi trường đơn bước có thực sự tốt và hiệu quả hay không? Do đó chúng tôi tiến hành nghiên cứu này với mục tiêu: Đánh giá bước đâu kết quả nuôi cấy phôi bằng môi trường đơn bước CSC và xác định một số yếu tố liên quan.

\section{II. ĐỐI TƯợNG VÀ PHƯƠNG PHÁP NGHIÊN CỨU}

2.1. Đối tượng nghiên cứu. Những người phụ nữ được thực hiện thụ tinh ống nghiệm bằng phương pháp tiêm tinh trù̀ng vào bào tương noãn (ICSI) tại Trung tâm Hỗ trợ sinh sản và Công nghệ mô ghép (HTSS \& CNMG), Bệnh Viện Đại học Y Hà Nội từ tháng 01/2021 đến tháng 08/2021. Thực tế nghiên cứu đã thu thập số liệu của 66 đối tượng với 1048 noãn thu được ở ngày chọc hút.

*Tiêu chuẩn lứa chọn: Thu được $\geq 4$ noãn ở ngày chọc hút, noãn sau ICSI được nuôi cấy hoàn toàn bằng môi trường đơn bước $\mathrm{CSC}$, hồ sơ có đầy đủ thông tin.

*Tiêu chuẩn loại trừ: Những trường hợp sử dụng tinh trùng đông lạnh hoặc tinh trùng trích xuất từ tinh hoàn hay mào tinh.

\subsection{Phương pháp nghiên cứu}

*Thiết kế nghiên cứu: Quan sát, mô tả theo dõi dọc.

\section{*Các bước tiến hành}

- Chọn mẫu phù hợp tiêu chuẩn. Phụ nữ trong nghiên cứu được kích thích buồng trứng bằng phác đồ antagonist, chọc hút noãn vào thời điểm sau tiêm trigger (hCG) 34 - 36 giờ. Đánh giá đặc điểm noãn.

- ICSI số noãn MII thu được theo quy trình thường quy, nuôi cấy trong môi trường đơn bước. Loại môi trường Continuous Single Culture-NX (CSC), hãng FUJIFILM Irvine Scientific, nuôi theo nhóm 3-4 noãn sau ICSI/giọt, thể tích 50pl/giọt.

- Đánh giá thụ tinh, chất lượng phôi ngày 2 , chuyển phôi sang đĩa nuôi cấy chứa môi trường CSC mới.

- Đánh giá tỷ lệ hình thành và chất lượng phôi nang. Các tiêu chuẩn đánh giá dựa vào mức độ phát triển khoang phôi nang, đặc điểm hình thái khối tế bào mầm phôi và lá nuôi tác giả Gardner D. K. (1999).

- Xác định mối liên quan giữa độ tuổi, chất lượng noãn và tinh trùng thời điểm ICSI đến các tỷ lệ phôi học (tỷ lệ thụ tinh, tỷ lệ tạo phôi ngày 2 , tỷ lệ hình thành phôi nang, tỷ lệ phôi nang hữu dụng).

\subsection{Biến số nghiên cứu}

*Đăc điểm chung: Tuổi, BMI, số năm vô sinh, số chu kỳ IVF/ICSI đã thực hiện.

\section{*Đặc điểm noãn, tinh trùng tại thời điểm} ICSI

- Số lượng, phân loại độ trưởng thành noãn (GV, MI, MII).

- Phân loại chất lượng noãn MII (bình thường và xấu) theo thường quy tại Trung tâm dựa trên Đồng thuận đánh giá và phân loại noãn, phôi trong hỗ trợ sinh sản (2012). Phân loại noãn xấu khi quan sát thấy một trong các đặc điểm: Lưới nội bào rõ, bào tương quánh, màng bào tương bở, màng trong suốt (ZP) dày đen, khối hạt 
trung tâm bào tương (CLG), khoảng quanh noãn hẹp hoặc rộng.

- Noãn thoái hóa, noãn bất thường sẽ loại khỏi nghiên cứu. Noãn bất thường khi có $\geq 2$ cực cầu hoặc kích thước khổng lồ.

- Phân loại tinh trùng (bình thường và xấu): Phân loại xấu khi $100 \%$ tinh trùng ICSI có bất thường về hình thái (theo thường quy tại trung tâm dựa trên tiêu chuẩn của WHO 2010).

*Đăc điểm phôi học

- Tỷ lệ thụ tinh = số lượng noãn thụ tinh / tổng số noãn MII được ICSI.

- Tỷ lệ tạo phôi ngày 2 = số phôi ngày 2 / tổng số noãn thụ tinh.

- Tỷ lệ tạo phôi nang = số phôi nang / tổng số phôi ngày 2.

- Tỷ lệ phôi nang hữu dụng = số phôi tốt và trung bình (phân loại $\geq 3 \mathrm{BB}$ ) /tổng số phôi nang (Ahlstrom A, 2011) [5].

- Phân loại phôi ngày 2 và phôi nang.

- Xác định mối liên quan giữa độ tuổi, chất lượng noãn, tinh trùng tại thời điểm ICSI tới các tỷ lệ phôi học.

2.4. Xử lý số liệu. Sử dụng phần mềm SPSS 20.0. Biến định tính được mô tả bằng tần số và tỷ lệ \%. Biến định lượng được mô tả bằng $X \pm$ $\mathrm{SD}$, min, max.

Sử dụng test ANOVA để so sánh các trung bình (>2): So sánh các tỷ lệ phôi học giữa các nhóm tuổi phụ nữ, giữa các nhóm chất lượng noãn và tinh trùng.

2.5. Đạo đức trong nghiên cứu. Nghiên cứu thuộc loại quan sát mô tả, theo dõi doc, không can thiệp trên bệnh nhân và được sự cho phép của lãnh đạo Trung tâm HTSS \& CNMG, Bệnh viện Đại học $Y$ Hà Nội. Thông tin bệnh nhân được mã hoá, giữ bí mật và chỉ phục vụ cho mục đích nghiên cứu.

\section{KẾT QUẢ NGHIÊN CỨU}

Nghiên cứu 66 đối tượng thực hiện chu kì ICSI với 1048 noãn thu được ở ngày chọc hút ghi nhận các kết quả sau.

3.1. Đặc điểm chung của đối tượng nghiên cứu

Bảng 1: Đặc điểm chung của phụ nữ trong nghiên cứu ( $n=66)$

\begin{tabular}{|c|c|c|c|}
\hline Chỉ số & $\begin{array}{c}\text { Trung bình } \\
(X \pm \text { SD) }\end{array}$ & Min & Max \\
\hline Tuối (năm) & $31,03 \pm 5,04$ & 22 & 46 \\
\hline BMI (kg/m²) & $20,97 \pm 3,22$ & 16,65 & 39,86 \\
\hline $\begin{array}{c}\text { Thời gian vồ } \\
\text { sinh (năm) }\end{array}$ & $3,94 \pm 3,41$ & 1 & 18 \\
\hline $\begin{array}{c}\text { Số chu kì } \\
\text { IVF/ICSI }\end{array}$ & $0,50 \pm 1,10$ & 0 & 7 \\
\hline
\end{tabular}

Các phụ nữ trong nghiên cứu chủ yếu nằm trong độ tuổi sinh sản $(31,03 \pm 5,04$ tuổi $)$. BMI trung bình trong giới hạn bình thường $(20,97 \pm$ $\left.3,22 \mathrm{~kg} / \mathrm{m}^{2}\right)$. Thời gian vô sinh trung bình 3,94 \pm 3,41 năm.

Bảng 2: Đặc điểm noãn của phụ nữ trong nghiên cứu (n = 1048)

\begin{tabular}{|c|c|c|c|c|c|}
\hline Đăc điếm noãn & $\mathbf{n}$ & $\mathbf{\%}$ & Trung bình (X $\mathbf{\pm}$ SD) & Min & Max \\
\hline GV & 36 & 3,44 & $0,55 \pm 1,03$ & 0 & 4 \\
\hline MI & 69 & 6,58 & $1,05 \pm 1,31$ & 0 & 6 \\
\hline MII & $\mathbf{8 0 6}$ & $\mathbf{7 6 , 9 1}$ & $\mathbf{1 2 , 2 1} \pm \mathbf{6 , 6 2}$ & $\mathbf{4}$ & $\mathbf{3 2}$ \\
\hline Thoái hóa & 86 & 8,21 & $1,30 \pm 1,45$ & 0 & 5 \\
\hline Bất thường & 51 & 4,87 & $0,77 \pm 1,17$ & 0 & 5 \\
\hline Tống & 1048 & 100 & $15,88 \pm 8,17$ & 5 & 41 \\
\hline
\end{tabular}

Số noãn trung bình thu được ở ngày chọc hút noãn của một phụ nữ trong nhóm nghiên cứu là $15,88 \pm 8,17$, ít nhất là 5 , nhiều nhất là 41 . Trong đó, số noãn MII trung bình là $12,21 \pm$ 6,62 ít nhất là 4 , nhiều nhất là 32 . Tổng số noãn MII thu được là 806 , chiếm $76,91 \%$, chỉ noãn MII được ICSI và tiếp tục theo dôii nuôi cây.

3.3. Đánh giá kết quả phôi học. 806 noãn trưởng thành (MII) được ICSI và nuôi cấy đến ngày 2 , trong số đó có 479 noãn sau ICSI tạo ra 421 phôi ngày 2 được theo dõi nuôi cấy liên tục đến ngày 5 . Thời điểm kiểm tra thụ tinh trung bình là 18,52 $\pm 1,78$ giờ sau ICSI. Giờ kiểm tra phôi ngày 2 trung bình là $45,37 \pm 2,81$ giờ. Giờ kiểm tra phôi ngày 5 trung bình là $115,62 \pm 3,67$ giờ.
Bảng 3: Kêt quả phôi học của đôí tượng nghiên cứu

\begin{tabular}{|c|c|c|c|}
\hline Thông số & $n / N$ & $\%$ & $\begin{array}{l}\text { Tỷ lệ trung } \\
\text { bình theo } \\
\text { từng bệnh } \\
\text { nhân } \\
\left(X^{ \pm} \text {SD) }\right.\end{array}$ \\
\hline Tỷ lệ thụ tinh & $\begin{array}{l}725 / \\
806\end{array}$ & 89,95 & $\begin{array}{c}91,66 \pm \\
12,92 \\
\end{array}$ \\
\hline $\begin{array}{c}\text { Tỷ lệ tạo phôi } \\
\text { ngày } 2\end{array}$ & $\begin{array}{l}715 / \\
725\end{array}$ & 98,62 & $98,34 \pm 5,40$ \\
\hline $\begin{array}{c}\text { Tỷ lệ tạo phôi } \\
\text { nang }\end{array}$ & $\begin{array}{l}311 / \\
\mathbf{4 2 1} \\
\end{array}$ & 73,87 & $\begin{array}{c}73,07 \pm \\
13,06 \\
\end{array}$ \\
\hline $\begin{array}{c}\text { Tỷ lệ phôi nang } \\
\text { hữu dụng } \\
\end{array}$ & 19/311 & 70,42 & $\begin{array}{c}69,81 \pm \\
12,96 \\
\end{array}$ \\
\hline
\end{tabular}


Tỷ lệ thụ tinh là $89,95 \%$ (trung bình $91,66 \pm$ $12,92 \%$ ), tỷ lệ tạo phôi ngày 2 là $98,62 \%$ (trung bình $98,34 \pm 5,40 \%)$. Tỷ lệ tạo phôi nang và tỷ lệ phôi nang hữu dụng lần lượt là 73,07 \pm $13,06 \%, 69,81 \pm 12,96 \%$.

3.4. Chất lượng phôi ngày 2 và phôi nang

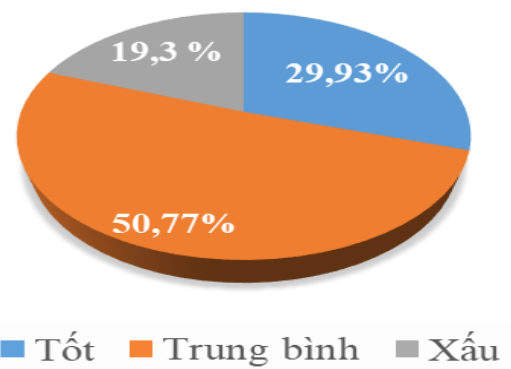

Biểu đồ 1: Chất lượng phôi ngày 2

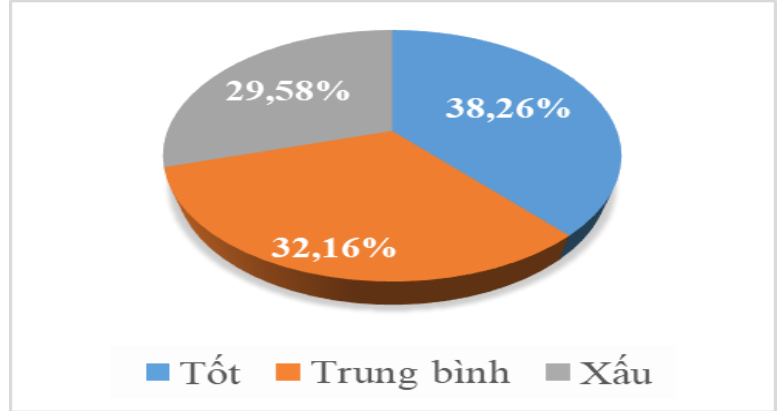

Biểu đồ 2: Chât lượng phôi nang

Phôi ngày 2 chất lượng trung bình chiếm tỷ lệ cao nhất $(50,77 \%)$, chất lượng xâu chiếm tỷ lể thấp nhất $(19,3 \%)$. Phôi nang chất lượng tốt chiếm 38,26\%, phôi nang hữu dụng chiếm $70,42 \%$.

\subsection{Một số yếu tố liên quan}

Bảng 4: Liên quan giữa nhóm tuổi và các thông số phôi học

\begin{tabular}{|c|c|c|c|c|}
\hline \multirow{2}{*}{ Đánh giá } & Tuổi $<30$ & $\mathbf{3 0} \leq \mathbf{t u o ̂ ́} i \leq 35$ & Tuổi $>\mathbf{3 5}$ & \multirow{2}{*}{ * } \\
\cline { 2 - 5 } & $\mathbf{n = 2 3}$ & $\mathbf{n = 3 1}$ & $\mathbf{n = 1 2}$ & \\
\hline Tý lệ thụ tinh (\%) & $87,80 \pm 17,44$ & $92,72 \pm 9,35$ & $96,34 \pm 9,01$ & $>0,05$ \\
\hline Tỷ lệ tạo phồi ngày 2(\%) & $97,76 \pm 7,28$ & $98,77 \pm 3,42$ & $98,34 \pm 5,77$ & $>0,05$ \\
\hline & $\mathbf{n = 9}$ & $\mathbf{n = 1 7}$ & $\mathbf{n = 3}$ & \\
\hline Tỷ lệ tạo phôi nang (\%) & $69,66 \pm 15,94$ & $74,98 \pm 12,04$ & $72,46 \pm 11,27$ & $>0,05$ \\
\hline Tỷ lệ phôi nang hữu dụng (\%) & $70,96 \pm 14,19$ & $70,25 \pm 12,46$ & $63,83 \pm 15,55$ & $>0,05$ \\
\hline
\end{tabular}

*p được tính theo so sánh phương sai ANOVA một yếu tố

Tỷ lệ tạo phôi ngày 2, tỷ lệ tạo phôi nang cao nhất ở nhóm 30 - 35 tuổi, lần lượt là $98,77 \pm$ $3,42 \% ; 74,98 \pm 12,04 \%$. Tỷ lệ phôi nang hữu dụng cao nhất ở nhóm $<30$ tuối $(70,96 \pm 14,19 \%)$. Tuy nhiên các chỉ số này không có sự khác biệt giữa các nhóm tuổi $(p>0,05)$.

Bảng 5: Liên quan giữa chất lượng noãn, tinh trùng với các thống số phôi học

\begin{tabular}{|c|c|c|c|c|c|}
\hline Đánh giá & $\begin{array}{c}\text { Noãn xấu } \\
n=15\end{array}$ & $\begin{array}{c}\text { Tinh trùng } \\
\text { xấu } \\
n=15\end{array}$ & $\begin{array}{c}\text { Noãn, tinh } \\
\text { trùng xấu } \\
n=10\end{array}$ & $\begin{array}{c}\begin{array}{c}\text { Bình } \\
\text { thường }\end{array} \\
\mathbf{n = 2 6}\end{array}$ & p* \\
\hline Tỷ lệ thụ tinh (\%) & $90,23 \pm 10,31$ & $94,91 \pm 7,86$ & $74,44 \pm 20,83$ & $97,24 \pm 5,01$ & $<0,05$ \\
\hline Tỷ lệ tạo phôi ngày $2(\%)$ & $95,74 \pm 9,82$ & $99,17 \pm 2,20$ & $98,33 \pm 5,27$ & $99,35 \pm 1,89$ & $>0,05$ \\
\hline & & & & $\mathrm{n}=\mathbf{1 0}$ & \\
\hline Tỷ lệ tạo phôi nang (\%) & $75,81 \pm 8,67$ & $76,82 \pm 15,75$ & 55,56 & $72,82 \pm 8,80$ & $>0,05$ \\
\hline $\begin{array}{l}\text { Tý lệ phôi nang hữu } \\
\text { dụng (\%) }\end{array}$ & $62,33 \pm 2,73$ & $67,74 \pm 14,31$ & $60,00 \pm 17,32$ & $78,75 \pm 8,22$ & $<0,05$ \\
\hline
\end{tabular}

*p được tính theo so sánh phương sai ANOVA một yếu tố

Tất cả thông số phôi học ở bảng 5 đều thấp nhất ở nhóm noãn xấu và tinh trùng xấu. Không có sự khác biệt về tỷ lệ tạo phôi ngày 2 và tạo phôi nang giữa các nhóm ( $p>0,05)$.

Tỷ lể thụ tinh và tỷ lể phôi nang hữu dụng cao nhất ở nhóm có chất lượng noãn và tinh trùng bình thường, lần lượt là 97,24 $\pm 5,01 \%$; $78,75 \pm 8,22 \%$, sự khác biệt giữa các nhóm có ý nghĩa thống kê $(p<0,05)$.

\section{BÀN LUÂ̂N}

Nghiên cứu được thực hiện trên 66 bệnh nhân đủ điều kiện với 806/1048 noãn trưởng thành (MII) được ICSI tại Trung tâm HTSS \& CNMG, Bệnh viện Đại học $Y$ Hà Nội (bảng 1,2). Số noãn MII sau ICSI của mỗi bệnh nhân được nuôi cấy trong môi trường đơn bước CSC, trong đó có 479 noãn sau ICSI được theo dõi nuôi cây liên tục đến ngày 5 .

4.1. Về kêt quả phôi học. Trong nghiên cứu này, tỷ lệ thụ tinh trung bình đạt $91,66 \pm$ $12,92 \%$ (bảng 3). Kết quả này của chúng tôi cao hơn một số tác giả cùng nghiên cứu nuôi cấy phôi trền môi trường đơn bước CSC như Ioannis A. Sfontouris và cs $(2017)(72,4 \%)$ hay của nhóm tác giả Danilo Cimadomo (2018) (71,0 \pm 
27,8\%)[6], [7]. Có sự khác biệt như vậy vì chúng tôi chỉ ghi nhận kết quả ICSI của những noãn MII, loại trừ noãn bất thường hay trường hợp nuôi trứng chưa trưởng thành và ICSI (in vitro maturation - IVM). Mặt khác, phần lớn các bệnh nhân làm thụ tinh trong ống nghiệm tại Trung tâm được nuôi cấy phôi đến ngày 2 và đông phôi toàn bộ hoặc chuyển phôi tươi vào ngày 3 . Những bệnh nhân có nhiêu phôi và chất lượng phôi ngày 2 đủ điều kiện mới được nuôi đển ngày 5 . Cũng không thể phủ nhận tỉ lệ thụ tinh cao liên quan đến trình độ chuyên môn và tay nghề của các nhà Phôi học tại Trung tâm.

Tỷ lệ tạo phôi giai đoạn phân cắt (ngày 2) đạt $98,34 \pm 5,40 \%$. Điều này tương tự như nghiển cứu của Ioannis A. Sfontouris và cs (2017) (98,9\%, sử dụng môi trường nuôi cấy đơn bước CSC) [6]. Kết quả trên cũng tương tự với nghiên cứu của nhóm tác giả Martin Stimpfel (2020) là $98 \%$ trong môi trường nuôi cấy đơn bước Sage 1-step medium (Origio) và G - TL medium (Vitrolife) [8]. Như vậy quy trình nuôi cấy phôi, loại môi trường lựa chọn, điều kiện labo tại Trung tâm HTSS \& CNMG, Bệnh viện Đại học Y Hà Nội đang hoạt động có hiệu quả và tương đồng với một số trung tâm khác trên thế giới.

Nghiên cứu của chúng tôi ghi nhận tỷ lệ phôi nang hữu dụng là $69,81 \pm 12,96 \%$, tỷ lệ này cao hơn của tác giả Ioannis A Sfontouris và cs (2017) nghiên cứu 252 noãn nuôi cấy trong môi trường CSC $(54,7 \%), 250$ noãn nuôi cấy trong môi trường đơn bước Sage one-step $(55,4 \%)$ hay Iratxe Lóspez-Pelayo và cs nghiên cứu trên 686 noãn MII ICSI (2018) (51,5\%) [8],[9]. Điểm khác biệt giữa nghiên cứu của chúng tôi với các nghiên cứu này là việc quyết định trường hợp tiếp tục nuôi cấy phôi liên tục đến ngày 5 , nhóm đối tượng của các tác giả khác đều được tiến hành nuôi toàn bộ phôi đến ngày 5 , còn chúng tôi dựa trên chất lượng phôi ngày 2 để quyết định. Do đó, những bệnh nhân có nhiều phôi ngày 2 tốt khi được nuổi cấy đến ngày 5 sẽ cho tỷ lệ phôi nang và phôi nang hữu dụng cao.

4.2. Về yếu tố liên quan. Trong nghiên cứu này, chúng tôi ghi nhận không có sự khác biệt ở tất cả các thông số phôi học về tỷ lệ thụ tinh, tỷ lệ tạo phôi ngày 2 , tỷ lệ tạo phôi nang, tỷ lệ phôi nang hữu dụng giữa các nhóm tuổi người phụ nữ (bảng 4). Cõ̃ mầu của nghiên cứu còn chưa đủ lớn $(n=66)$, nhóm tác giả sẽ tiếp tục tìm hiểu vấn đề này ở những nghiên cứu sau.

Về yếu tố chất lượng noãn và tinh trùng tại thời điểm ICSI: chúng tôi ghi nhận sự khác biệt có ý nghĩa thống kê về tỷ lệ thụ tỉnh và tỷ lệ phồi nang hữu dụng giữa các nhóm noãn xấu, tinh trùng xấu, cả noãn và tinh trùng xấu, cả noãn và tinh trùng bình thường $(p<0,05)$, trong đó các tỷ lệ này cao nhất ở nhóm noãn và tinh trùng bình thường, lần lượt là 97,24 $\pm 5,01 \% ; 78,75 \pm$ $8,22 \%$ (bảng 5 ). Như vậy chất lượng noãn và tinh trùng tại thời điểm ICSI đều xấu ảnh hưởng đến tỷ lệ thụ tinh và tỷ lệ phôi nang hữu dụng, làm giảm hiệu quả của một chu kỳ ICSI. Đây có thể là một gợi ý cho các nhà phôi học khi quyết định có nuôi cấy phôi đến ngày 5 hay không trên từng đối tượng cụ thể.

Nghiên cứu này của chúng tôi gợi ý rằng, việc quyết định nuôi cấy phôi liên tục đển ngày 5 nển được áp dụng đối với từng trường hợp bệnh nhẩn cụ thể dựa trên sự đánh giá chất lượng noãn và tinh trùng tại thời điểm ICSI, chất lượng phôi ngày 2 để tránh tình trạng bệnh nhân có thể không có phôi nang vào ngày 5 . Nhóm tác giả cần tiếp tục tìm hiểu, nghiên cứu sâu rộng hơn nhằm đánh giá hiệu quả nuôi cấy phôi bằng các hệ môi trường đơn bước khác nhau hoặc giữa môi trường đơn bước và môi trường chuyển tiếp chuyển tiếp, bên cạnh đó việc đánh giá nên hay không nên chuyển đĩa thay mới môi trường vào ngày 3 cũng đang được nhiêu tác giả quan tâm. Vấn đề này đã được đề cập đến trong nghiên cứu của tác giả Razek AAA và cs (2018) sử dụng môi trường nuôi cấy đơn bước (Single culture media Global ${ }^{\circledR}$ ), kết quả cho thấy việc thay mới môi trường vào ngày 3 giúp tăng tỷ lệ tạo phôi nang và phôi nang hữu dụng $(\mathrm{p}<0,001)$, tuy nhiên không có sư khác biêt về tỷ lệ thụ tinh, tỷ lệ tạo phôi phân cắt và chất lượng phôi phân cắt $(p>0,05)$.

\section{KẾT LUÂN}

Nuôi cãy phôi trong môi trường đơn bước CSC cho hiệu quả cao về tỷ lệ thụ tinh, tỷ lệ tạo phôi ngày 2 , tỷ lệ tạo phôi nang và tỷ lệ phôi nang hữu dụng với các kết quả lần lượt là 91,66 $\pm 12,92 \% ; 98,34 \pm 5,40 ; 73,07 \pm 13,06 \%$; $69,81 \pm 12,96 \%$.

Chất lượng noãn và tinh trùng tại thời điểm ICSI xấu làm giảm tỷ lệ thụ tinh và tỷ lệ tạo phôi nang hữu dụng $(p<0,05)$.

Lời cảm ơn: Nghiên cứu được thực hiện tại Trung tâm Hố trợ sinh sản và Công nghệ mô ghép, Bệnh viện Đại học $Y$ Hà Nội. Chúng tôi trân trọng cảm ơn lãnh đạo, nhân viên và bệnh nhân của Trung tâm đã tạo điều kiện cho chúng tôi thực hiện nghiên cứu này.

Các tác giả cam kết không có tranh chấp về quyền lợi trong nghiên cứu này. 


\section{TÀI LIÊU THAM KHẢO}

1. Leese H.J. (1998). Human Embryo Culture: Back to Nature. J Assist Reprod Genet, 15(8), 466-468.

2. Lawitts J.A. and Biggers J.D. (1991). Optimization of mouse embryo culture media using simplex methods. J Reprod Fertil, 91(2), 543-556.

3. Dieamant F., Petersen C.G., Mauri A.L., et al. (2017). Single versus sequential culture medium: which is better at improving ongoing pregnancy rates? A systematic review and meta-analysis. JBRA Assist Reprod, 21(3), 240-246.

4. Đặng Quang Vinh, Võ Nguyên Thức, Nguyễn Ngọc Quỳnh, và cs (2017). So sánh hiệu quả tạo phôi nang giữa hai loại môi trường nuôi cấy đơn bước và môi trường nuôi cấy chuyến tiếp. Tạp chí Phụ Sản, 14(4).

5. Ahlström A., Westin C., Reismer E., et al. (2011). Trophectoderm morphology: an important parameter for predicting live birth after single blastocyst transfer. Hum Reprod, 26(12), 3289-3296.
6. Sfontouris I.A., Kolibianakis E.M., Lainas G.T., et al. (2017). Blastocyst utilization rates after continuous culture in two commercial single-step media: a prospective randomized study with sibling oocytes. J Assist Reprod Genet, 34(10), 1377-1383.

7. Cimadomo D., Scarica C., Maggiulli R., et al. (2018). Continuous embryo culture elicits higher blastulation but similar cumulative delivery rates than sequential: a large prospective study. J Assist Reprod Genet, 35(7), 1329-1338.

8. Stimpfel M., Bacer-Kermavner L., Jancar N., et al. (2020). The influence of the type of embryo culture media on the outcome of IVF/ICSI cycles. Taiwan J Obstet Gynecol, 59(6), 848-854.

9. López-Pelayo I., Gutiérrez-Romero J.M., Armada A.I.M., et al. (2018). Comparison of two commercial embryo culture media (SAGE-1 step single medium vs. G1-PLUS ${ }^{T M} / G 2-$ PLUS $^{T M}$ sequential media): Influence on in vitro fertilization outcomes and human embryo quality. JBRA Assist Reprod, 22(2), 128-133.

\section{HIỆU QUẢ CỦA KỸ THUÂT KHÍ DUNG SÓNG CAO TẦN TRONG ĐIỀU TRI ĐỢT CẤP BÊ̂NH PHỔI TẮC NGHẼN MẠN TÍNH MỨC Độ TRUNG BÌNH}

\section{TÓM TẮT}

Mục tiêu nghiên cứu: Đánh giá hiệu quả kỹ thuật khí dung sóng cao tần (IPV) trong điểu trị bệnh nhân đợt cấp COPD mức độ trung bình. Phướng Pháp: Nghiên cứu tiến cứu can thiệp trên 60 bệnh nhân đợt cấp COPD mức độ trung bình theo tiêu chuẩn Anthonisen 1987, vào viện tại trung tâm Cấp cứu A9 - Bệnh viện Bạch Mai từ tháng 7 năm 2020 đến tháng 7 năm 2021, các bệnh nhân tham gia nghiên cứu đước chia thành hai nhóm, 30 bênh nhân nhóm chứng và 30 bệnh nhân nhóm can thiệp IPV. Các thông số theo dõi chính như: Tuổi, giới, các chỉ số lâm sàng: mạch, nhịp thở, Sp02 tại các thời điểm nhập viện (TO), sau khí dung 60 phút (T1), 6h (T2), 12h (T3), 24h(T4), 48h(T5), 72h(T6); các chỉ số khí máu: $\mathrm{pH}, \mathrm{PaCO} 2, \mathrm{PaO}_{2}, \mathrm{HCO}^{-}$, theo dõi tại các thời điểm T0, T2, T4, T5 và T6. Bệnh nhân được đánh giá thành cống khi không phải thở máy hố trợ. Kết quả: Trong 60 bệnh nhân nghiên cứu (tuổi trung bình $69,83 \pm 9,90$ tuổi; $11,7 \%$ nữ giới) cho kết quả: Có 6 (20\%) bệnh nhân trong nhóm chứng phải chuyển thở không xầm nhập, trong khí đó ở nhóm can thiệp có 1 (3,3\%) bệnh nhân trong nhóm phải chuyển thở không xâm nhập $(p<0,05)$. Thời gian nằm viện của nhóm

${ }^{1}$ Bệnh viện Hữu nghi Việt Tiệp - Hải Phòng ²Tung tâm Cấp cứu A9-Bênh viện Bạch Mai Chịu trách nhiệm chính: Đổ Ngọc Sơn Email: sonngocdo@gmail.com Ngày nhận bài: 13.7.2021

Ngày phản biên khoa hoc: 31.8.2021

Ngày duyệt bài: 15.9.2021
Trần Văn Tân ${ }^{1}$, Đỗ Ngọc Sơn ${ }^{2}$

chứng là $8,00 \pm 2,95$ ngày, của nhóm can thiệp là $6,73 \pm 2,99$ ngày $(p=0,105)$. Có $63,3 \%$ bệnh nhân đánh giá IPV ở mức độ dế chiu (mức đô I), $26,7 \%$ bệnh nhân đáng giá ở mức độ khó chịu nhẹ (mức độ II), không có bênh nhân nào khó chiu tới mức phải dứng khí dung bằng IPV. Kết luận: IPV là một kỹ thuật an toàn và có thể ngăn chặn tình trạng xầu đi của đợt cấp trong điều trị đợt cấp bệnh phổi tắc nghẽn mạn tính mức độ trung bình, giảm tỳ lệ bệnh nhân chuyển thở máy không xâm nhập.

Tì̛ khóa: Khí dung sóng cao tần, thông khí nhân tạo không xâm nhập, bệnh phổi tắc nghẽn mạn tính.

\section{SUMMARY \\ EFFECTIVENESS OF INTRAPULMONARY PERCUSSIVE VENTILATION IN THE TREATMENT OF PATIENTS WITH MILD TO MODERATE EXACERBATION OF CHRONIC PULMONARY OBSTRUCTIVE DISEASE}

Objective: To evaluate the effectiveness of intrapulmonary percussive ventilation (IPV) in the treatment of mild to moderate exacerbations of COPD patients. Methods: Prospective interventional study on 60 patients with acute exacerbation of COPD according to Anthonisen 1987, admitted to the Center for Emergency Medicine of Bach Mai Hospital from July 2020 to July 2021, of which 30 were assigned to standard treatment, and 30 to IPV. The main variables such as age, sex, vital signs parameters: heart rate, respiratory rate, saturation of peripheral oxygen (SpO2) at the time of admission (T0), 1 hour (T1), 6 hours (T2), 12 hours hours(T3), 24 hours (T4), 48 